\title{
Study of Co-Ni-Al Alloys with Magnetically Controlled Shape Memory Effect
}

\author{
I.I. Kositsyna ${ }^{\text {a }}$, V.A. Zavalishin ${ }^{\text {b }}$ \\ Institute of Metal Physics, Ural Branch RAS, 18 S. Kovalevskaya St., 620041 Ekaterinburg, Russia \\ e-mail: ${ }^{a k o s i t s y n a @ i m p . u r a n . r u},{ }^{b}$ zavali@imp.uran.ru
}

Keywords: ferromagnetic Co-Ni-Al alloys, phase composition, shape memory effect, melt spinning, microcrystalline structure.

\begin{abstract}
The methods of electron microscopy, resistometry and magnetometry are used to study ten (36-38) Co - (32-36) Ni - (27-30)Al (at. \%) alloys. Cast coarse-crystalline and microcrystalline alloys made by melt spinning in a helium atmosphere are considered. It is shown that the martensite start temperature $\mathrm{M}_{\mathrm{s}}$ becomes $30-50^{\circ} \mathrm{C}$ lower as grains are refined to $1 \mu \mathrm{m}$. Replacement of 1 at. $\%$ cobalt by nickel and 1 at. \% aluminum by nickel makes the temperature interval of the $\mathrm{B} 2 \leftrightarrow \mathrm{L} 1_{0}$ martensite transformation $(30-60)^{\circ} \mathrm{C}$ and $(100-110)^{\circ} \mathrm{C}$ higher respectively. The martensite transformation hysteresis is about 100 degrees. The melt-spun $\mathrm{Co}_{38} \mathrm{Ni}_{34} \mathrm{Al}_{28}$ alloy with the transformation temperatures $\mathrm{M}_{\mathrm{s}}=31^{\circ} \mathrm{C}, \mathrm{M}_{\mathrm{f}}=-34^{\circ} \mathrm{C}, \mathrm{A}_{\mathrm{s}}=-6^{\circ} \mathrm{C}, \mathrm{A}_{\mathrm{f}}=70^{\circ} \mathrm{C}$ and $\mathrm{T}_{\mathrm{c}}=98^{\circ} \mathrm{C}$ is a material possessing the magnetically controlled shape memory effect.
\end{abstract}

\section{Introduction}

Investigations of ferromagnets possessing the magnetically controlled shape memory effect (MCSME) are directed to creation of new functional materials, in which a quick response to an external effect would combine with large reversible deformations. The best achievements in this field are related to the Heusler alloys $\mathrm{Ni}_{2+\mathrm{x}+\mathrm{y}} \mathrm{Mn}_{1-\mathrm{x}} \mathrm{Ga}_{1-\mathrm{y}}$ [1]. An effort is made to expand the range of MCSME alloys. Properties like those observed in a classical Heusler alloy were detected both in structurally similar $\mathrm{Ni}_{2} \mathrm{MnAl}, \mathrm{Co}_{2} \mathrm{MnGa}$ and $\mathrm{Co}_{2} \mathrm{MnAl}$ alloys and in ferromagnetic alloys of fundamentally different systems, e.g., Fe-Pd and Fe-Pt or Co-Ni-Al and Co-Ni-Ga [2-6].

The nickel-aluminum paramagnetic $\mathrm{L}_{0}$ martensite $\left(\mathrm{Ni}_{64 \cdot 66} \mathrm{Al}_{36-34}\right.$ as the classical $\beta$-alloys) is assumed to be a functional material with a high-temperature shape memory effect [7]. As nickel is partially (up to $50 \%$ ) replaced by cobalt, the $\mathrm{L}_{0}$ martensite in these alloys passes from the paramagnetic to the ferromagnetic state. The $\mathrm{Co}-\mathrm{Ni}-\mathrm{Ga}$ and $\mathrm{Co}-\mathrm{Ni}-\mathrm{Al}$ systems have a similar configuration of the boundary between the $(\beta)$ one-phase and $(\beta+\gamma)$ two-phase regions in the corresponding equilibrium diagrams. As the temperature rises, this boundary shifts perceptibly towards the two-phase region, predetermining the possibility that a supersaturated $\beta$ solid solution is obtained by quenching from a high temperature. As the cobalt concentration increases, the martensitic transformation temperature drops sharply, but the Curie temperature becomes higher; the Curie temperature curves do not coincide for the $\mathrm{L} 1_{0}$ martensite and the $\beta$ austenite. The most interesting compounds from the viewpoint of their use as MCSME materials fall within a very narrow interval of concentrations (Fig. 1) [8].

The Co-Ni-Al system has long and widely been used as the basis of superalloys or heatresistant sputtered coatings [9]. Co-Ni-Al alloys are appealing as MCSME materials since their plasticity is sufficiently high in the polycrystalline (PC) and microcrystalline (MC) states as the interval of the compounds we are interested in is close to the boundary between the $(\beta)$ onephase and $(\beta+\gamma)$ two-phase regions (Fig. 1). These alloys can rather easily be plasticized by adding a small quantity of the plastic $\gamma$-component to the structure. The quantity of the $\gamma$-phase can be strictly controlled by the composition and the thermal treatment of the two-phase alloy. 


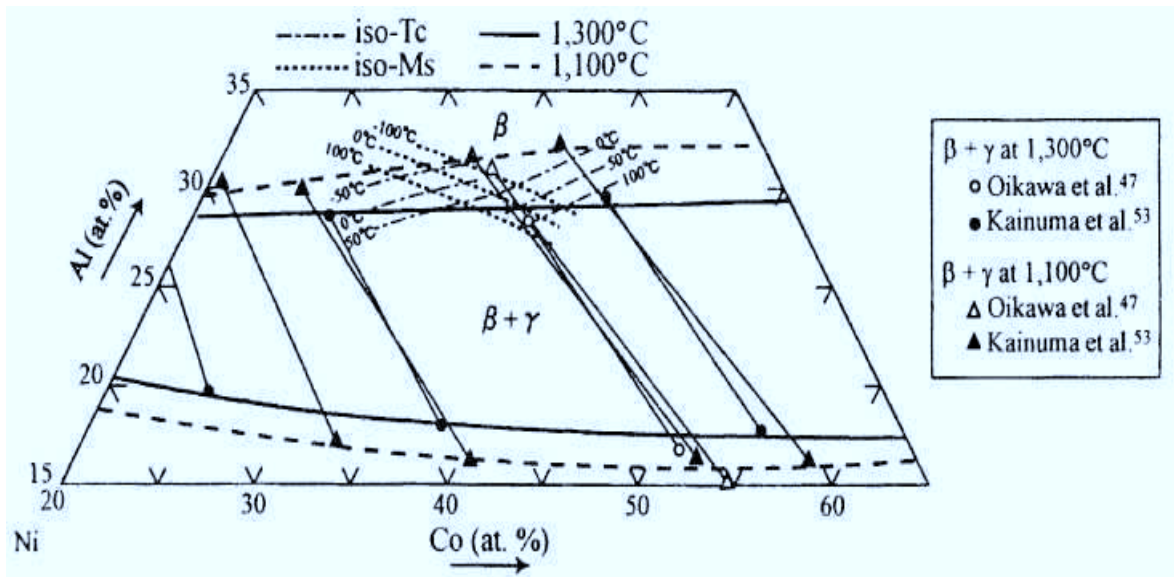

Fig. 1. Isotherms of the Curie temperature $\left(\mathrm{T}_{\mathrm{c}}\right)$ and the martensite start temperature $\left(\mathrm{M}_{\mathrm{s}}\right)$ of $\beta$ alloys plotted in the equilibrium diagram of Co-Ni-Al [8].

\section{Experimental}

The objects of study were ten $(\beta+\gamma)$ two-phase (36-38)Co - (32-36) Ni - (27-30)Al (at. \%) alloys in the PC and MC states: $\mathrm{Co}_{37} \mathrm{Ni}_{34} \mathrm{Al}_{29}, \mathrm{Co}_{38} \mathrm{Ni}_{33} \mathrm{Al}_{29}, \mathrm{Co}_{39} \mathrm{Ni}_{32} \mathrm{Al}_{29}, \mathrm{Co}_{38} \mathrm{Ni}_{34} \mathrm{Al}_{28}$, $\mathrm{Co}_{38} \mathrm{Ni}_{32} \mathrm{Al}_{30}, \mathrm{Co}_{38} \mathrm{Ni}_{33.5} \mathrm{Al}_{28.5}, \mathrm{Co}_{37} \mathrm{Ni}_{35} \mathrm{Al}_{28}, \mathrm{Co}_{38} \mathrm{Ni}_{35} \mathrm{Al}_{27}, \mathrm{Co}_{37} \mathrm{Ni}_{36} \mathrm{Al}_{27}$ and $\mathrm{Co}_{36} \mathrm{Ni}_{36} \mathrm{Al}_{28}$. The PC alloys were made by casting to a copper mold and subsequent quenching from $1200^{\circ} \mathrm{C}$. The $\mathrm{MC}$ alloys were smelted of pure metals by spinning of the melt on a quickly rotating steel drum in a helium atmosphere. The crystallization cooling rate was not less than $10^{4} \mathrm{~K} / \mathrm{s}$. Strip samples $2 \times 0.02$ $\mathrm{mm}$ in cross section were obtained. The microhardness was measured under a load of $0.5 \mathrm{~N}$ using unetched metallographic sections of PC samples (after casting and after quenching) and cross sections of MC strips. The resistometric measurements were performed during linear heating and cooling of the samples at temperatures from -150 to $600^{\circ} \mathrm{C}$. A Faraday magnetic balance was used to determine the temperature dependence of the specific magnetization of the samples at temperatures of $(20-220)^{\circ} \mathrm{C}$ in a constant magnetic field of $0,5 \mathrm{kOe}$. The structure was examined in a optical microscope and by the method of transmission electron microscopy in a JEM-200CX microscope.

\section{Results and Discussion}

The alloys under study inherit a high hardness from the NiAl and CoAl intermetallics. The hardness of all the alloys in the cast PC state is within 4500-5500 MPa. Subsequent to annealing at $1200^{\circ} \mathrm{C}$ for $5 \mathrm{~h}$ and quenching in water the microhardness of the alloys was $5000 \pm 100 \mathrm{MPa}$ and was determined by the microhardness of the ordered $\beta$ solid solution as the volume fraction of the plastic $\gamma$ solid solution was small. Subsequent to spinning the microhardness decreased to 4600$4800 \mathrm{MPa}$ on account of the defectness (microporosity) of the thin cast strip. This micro defects did not allow estimating the standard mechanical properties of the alloys in the MC state as the strips were broken in the defective area at the stage of elastic deformation.

The analysis of the structure of the samples, which were cast to a copper mold and quenched from $1200^{\circ} \mathrm{C}$, demonstrated that most of the alloys fell within the two-phase $(\beta+\gamma)$ region at the boundary with the one-phase $\beta$ region in the Co-Ni-Al ternary diagram, while the $\mathrm{Co}_{38} \mathrm{Ni}_{32} \mathrm{Al}_{30}$ alloy containing $30 \%$ aluminum belonged, on the contrary, to the one-phase $\beta$ region at the boundary with the two-phase $(\beta+\gamma)$ region. The main phase component of all the alloys under study was an ordered $\beta$ (B2) solid solution providing a clear-cut tweed contrast (Fig. 2a). In other words, the martensite point $\mathrm{M}_{\mathrm{s}}$ in the majority of the cast PC alloys (except $\mathrm{Co}_{37} \mathrm{Ni}_{36} \mathrm{Al}_{27}$ and 
$\mathrm{Co}_{36} \mathrm{Ni}_{36} \mathrm{Al}_{28}$ ) was below room temperature after quenching. The small $\gamma$-phase particles were observed on the grain boundaries in some of the PK alloys.

Subsequent to spinning the alloys passed to the MC state and the grain size decreased to 1-4 $\mu \mathrm{m}$. At room temperature all the alloys, except $\mathrm{Co}_{38} \mathrm{Ni}_{34} \mathrm{Al}_{28}, \mathrm{Co}_{37} \mathrm{Ni}_{36} \mathrm{Al}_{27}$ and $\mathrm{Co}_{36} \mathrm{Ni}_{36} \mathrm{Al}_{28}$, remained to be $\beta$ (B2) austenitic alloys highly supersaturated with transition elements. The point $\mathrm{M}_{\mathrm{S}}$ in the alloys with $28 \% \mathrm{Al}$ was slightly above room temperature and up to $50 \% \mathrm{~L}_{0}$ martensite appeared in the structure (Fig. 2b).
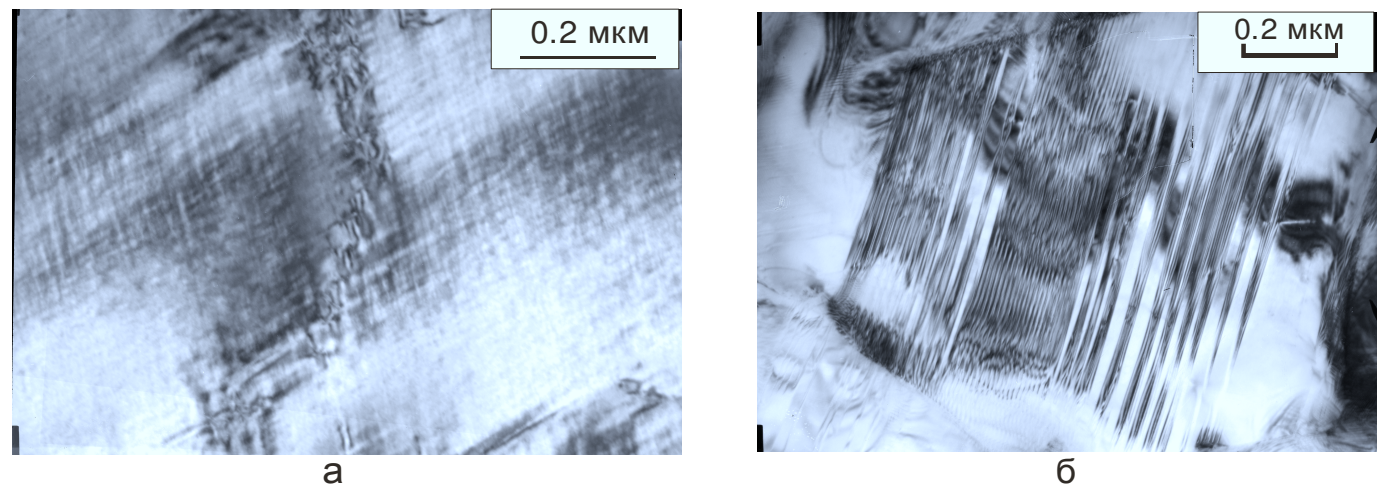

Fig. 2. Structure of the $\mathrm{Co}_{38} \mathrm{Ni}_{34} \mathrm{Al}_{28}$ alloy after standard casting and water quenching from $1200^{\circ} \mathrm{C}$ (a); after spinning (b) $[9,10]$.

To determine temperature intervals of phase transformations in the MC alloys, we measured the temperature dependence of the electrical resistance of thin strip samples and plotted curves showing the change of the relative electrical resistance during linear heating and cooling over the temperature interval of -150 to $600^{\circ} \mathrm{C}$. (Fig. 3) [9, 10]. The electrical resistance of all the alloys varied almost similarly at positive temperatures. At temperatures of $315-370^{\circ} \mathrm{C}$ (the temperature correlated directly with the aluminum concentration of the alloys) a linear temperature ascent was replaced by the descent of the curve, which was due to the diffusion decomposition of the supersaturated $\beta$ solid solution. At temperatures of $(480-500)^{\circ} \mathrm{C}$ the decomposition processes leading to the impairment of the electrical resistance were complete in all the five alloys and the electrical resistance dropped almost linearly with temperature in the new stable phase state during cooling. The electrical resistance of all the five alloys decreased by $\sim 25 \%$ after the $20^{\circ} \mathrm{C} \rightarrow 600^{\circ} \mathrm{C} \rightarrow 20^{\circ} \mathrm{C}$ thermal cycle. This is explained by the transition of an unstable (after melt spinning) state to an annealed stable state.

Of greatest interest is the temperature dependence of the relative electrical resistance of the alloys under study over the interval of cryogenic temperatures. The left-hand branches of the curves exhibit temperature hysteresis loops characteristic of the thermoelastic martensite transformation: the $\mathrm{B} 2 \rightarrow \mathrm{L} 1_{0}$ martensite transformation is followed by a sharp rise of the electrical resistance, whereas the electrical resistance drops during the reverse transformation. The analysis of these loops by the tangent method allowed determining the characteristic martensite points: $M_{\mathrm{s}}$ and $\mathrm{M}_{\mathrm{f}}$ are the start and finish temperatures of the forward $\mathrm{B} 2 \rightarrow \mathrm{L} 1_{0}$ martensite transformation; $\mathrm{A}_{\mathrm{s}}$ and $\mathrm{A}_{\mathrm{f}}$ are the start and finish temperatures of the reverse shear $\mathrm{L} 1_{0} \rightarrow \mathrm{B} 2$ transformation (Table 1). For comparison the same table gives the martensite transformation temperature $\left(\mathrm{M}_{\mathrm{s}}\right)$ and the Curie temperature $\left(\mathrm{T}_{\mathrm{c}}\right)$ for the coarse-grain state [9-12].

In the MC alloys under study the concentration dependence of the martensite transformation temperature is qualitatively similar to the corresponding dependence in the PC alloys of an analogous composition. At the same time, the effect of the size of B2 austenitic grains is clearly seen. The reversible martensite transformation takes place at lower temperatures in alloys with ultrafine grains than in coarse-grain polycrystalline alloys. For example, the difference is 50 degrees in $\mathrm{Co}_{37} \mathrm{Ni}_{34} \mathrm{Al}_{29}$, 30 degrees in $\mathrm{Co}_{38} \mathrm{Ni}_{33} \mathrm{Al}_{29}$, and 51 degrees in $\mathrm{Co}_{39} \mathrm{Ni}_{32} \mathrm{Al}_{29}$. If the aluminum concentration is constant (29 at. \%) and the nickel concentration increases at the expense of the 
cobalt content $\left(\mathrm{Co}_{39} \mathrm{Ni}_{32} \mathrm{Al}_{29} \rightarrow \mathrm{Co}_{38} \mathrm{Ni}_{33} \mathrm{Al}_{29} \rightarrow \mathrm{Co}_{37} \mathrm{Ni}_{34} \mathrm{Al}_{29}\right)$, the martensitic hysteresis loop shifts considerably to the right (30-60 degrees per 1 at. \% nickel), but the decomposition start temperature of the supersaturated $\beta$ solid solution changes little $\left(345 \pm 5^{\circ} \mathrm{C}\right)$. However, if the nickel concentration increases at the expense of the aluminum content and the cobalt concentration is constant $\left(\mathrm{Co}_{38} \mathrm{Ni}_{32} \mathrm{Al}_{30} \rightarrow \mathrm{Co}_{38} \mathrm{Ni}_{33} \mathrm{Al}_{29} \rightarrow \mathrm{Co}_{38} \mathrm{Ni}_{34} \mathrm{Al}_{28}\right)$, the temperatures of the martensite transformation and the diffusion decomposition change to a much greater extent. For example, addition of 1 at. $\%$ nickel $\left(\mathrm{Co}_{38} \mathrm{Ni}_{33} \mathrm{Al}_{29} \rightarrow \mathrm{Co}_{38} \mathrm{Ni}_{34} \mathrm{Al}_{28}\right)$ shifts the onset of the martensite transformation to the right by $110^{\circ} \mathrm{C}$ and the diffusion decomposition of the supersaturated $\beta$ solid solution to the left by $(20-30)^{\circ} \mathrm{C}$. The width of the martensite transformation interval $\left(\mathrm{M}_{\mathrm{s}}-\mathrm{M}_{\mathrm{f}}\right.$ and $\mathrm{A}_{\mathrm{f}}-\mathrm{A}_{\mathrm{s}}$ ) in the $\mathrm{Co}_{37} \mathrm{Ni}_{34} \mathrm{Al}_{29}, \mathrm{Co}_{38} \mathrm{Ni}_{33} \mathrm{Al}_{29}$ and $\mathrm{Co}_{38} \mathrm{Ni}_{34} \mathrm{Al}_{28}$ alloys is between 45 and 75 degrees, while the full width of the martensite transformation hysteresis $\left(A_{f}-M_{f}\right)$ is 90 to 110 degrees. Thus, the replacement of 1 at. $\%$ cobalt by nickel and 1 at. $\%$ aluminum by nickel in $\mathrm{Co}-\mathrm{Ni}-\mathrm{Al}$ ferromagnetic alloys increases the temperature interval of the $\mathrm{B} 2 \rightarrow \mathrm{L} 1_{0}$ martensite transformation by $(30-60)^{\circ} \mathrm{C}$ and $(100-110)^{\circ} \mathrm{C}$ respectively. The martensite transformation hysteresis is about 100 deg. wide.

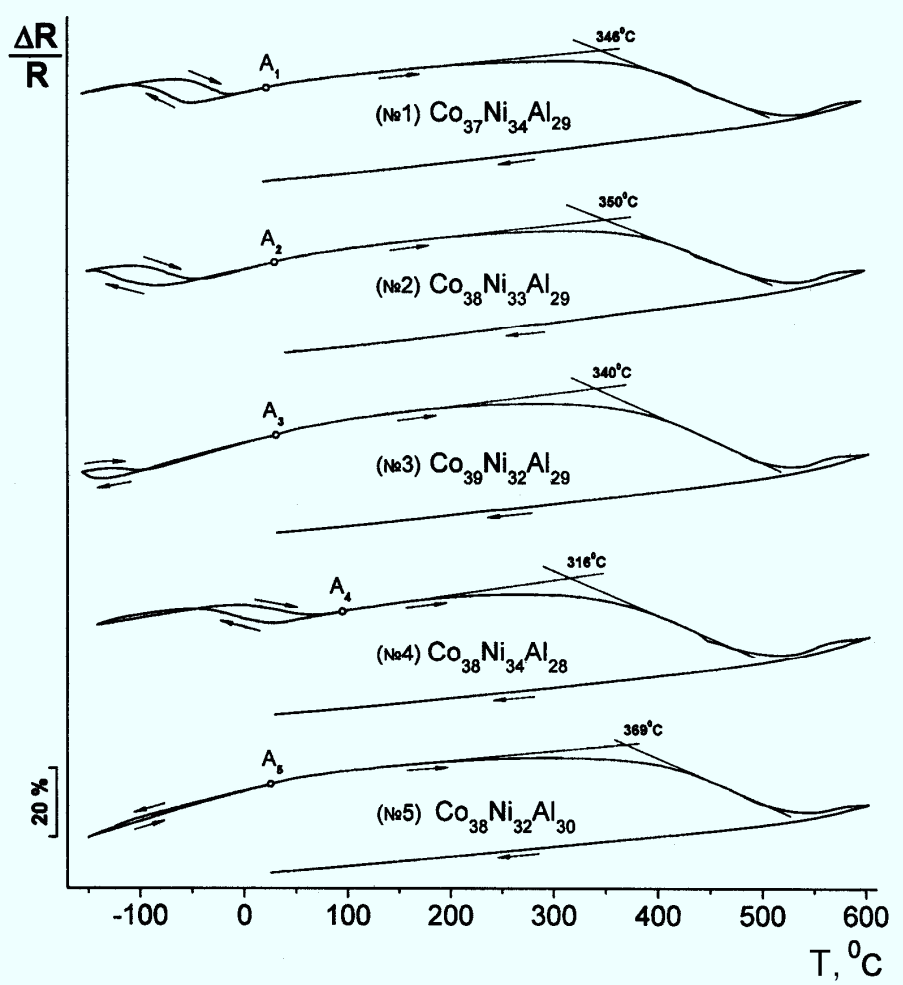

Fig. 3. Temperature dependence of the relative electrical resistance of Co-Ni-Al MC alloys with a linear variation of the temperature $\left({ }^{\circ} \mathrm{C}\right): 20 \rightarrow-50 \rightarrow 20 \rightarrow 600 \rightarrow 20[9,10]$.

All the alloys under study were in the ferromagnetic state at room temperature. A Faraday magnetic balance was used to establish the temperature dependence of the specific magnetization of the samples over the temperature interval of $(20-220)^{\circ} \mathrm{C}$ in a constant magnetic field of $0,5 \mathrm{kOe}$. The heating and cooling curves coincide for the $\mathrm{Co}_{37} \mathrm{Ni}_{34} \mathrm{Al}_{29}, \mathrm{Co}_{38} \mathrm{Ni}_{33} \mathrm{Al}_{29}, \mathrm{Co}_{39} \mathrm{Ni}_{32} \mathrm{Al}_{29}$ and $\mathrm{Co}_{38} \mathrm{Ni}_{32} \mathrm{Al}_{30}$ alloys, whereas the cooling curve is considerably higher than the heating curve (Fig. 4) for the $\mathrm{Co}_{38} \mathrm{Ni}_{34} \mathrm{Al}_{28}$ and $\mathrm{Co}_{36} \mathrm{Ni}_{36} \mathrm{Al}_{28}$ alloys during cooling over the interval of $(70-20)^{\circ} \mathrm{C}$. The observed hysteresis can be due to the contribution made by the reverse martensite transformation to the trend of the heating curve over this temperature interval. Cobalt has the largest effect on the magnetic properties: as its concentration increases by 1 at. \%, the specific magnetization rises by $5.0 \mathrm{Gs} \mathrm{cm}^{3} \mathrm{~g}^{-1}$ at $20^{\circ} \mathrm{C}$. Values of the Curie temperature (Table 1) also suggest a strong direct dependence of $T_{c}$ on the cobalt concentration and its inverse dependence on the aluminum and 
nickel concentrations. A large value (near $100^{\circ} \mathrm{C}$ ) of $\mathrm{T}_{\mathrm{c}}$ in the $\mathrm{Co}_{38} \mathrm{Ni}_{34} \mathrm{Al}_{28}, \mathrm{Co}_{38} \mathrm{Ni}_{35} \mathrm{Al}_{27}$ and $\mathrm{Co}_{37} \mathrm{Ni}_{36} \mathrm{Al}_{27}$ alloys is remarkable.

Table 1. Martensite transformation temperatures $\left(\mathrm{M}_{\mathrm{s}}, \mathrm{M}_{\mathrm{f}}, \mathrm{A}_{\mathrm{f}}, \mathrm{A}_{\mathrm{s}}\right)$ and the Curie temperature $\left(\mathrm{T}_{\mathrm{c}}\right)$ for Co-Ni-Al MC and PC alloys $\left({ }^{\circ} \mathrm{C}\right)$

\begin{tabular}{|c|c|c|c|c|c|c|c|c|}
\hline No. & $\begin{array}{c}\text { Co-Ni-Al } \\
\text { composition, } \\
\text { at.\% }\end{array}$ & \multicolumn{9}{|c|}{ MC alloys } & \multicolumn{2}{c|}{ PC alloys } \\
\cline { 2 - 9 } & $\mathrm{M}_{\mathrm{s}}$ & $\mathrm{M}_{\mathrm{f}}$ & $\mathrm{A}_{\mathrm{s}}$ & $\mathrm{A}_{\mathrm{f}}$ & $\mathrm{T}_{\mathrm{c}}$ & $\mathrm{M}_{\mathrm{s}}$ & $\mathrm{T}_{\mathrm{c}}$ \\
\hline 1 & $37-34-29$ & -53 & -104 & -61 & -15 & 27 & -3 & 7 \\
\hline 2 & $38-33-29$ & -80 & -142 & -106 & -46 & 54 & -50 & 50 \\
\hline 3 & $39-32-29$ & -141 & $<-160$ & $<-160$ & -95 & 75 & -90 & 70 \\
\hline 4 & $38-34-28$ & 31 & -34 & -6 & 70 & 98 & 20 & - \\
\hline 5 & $38-32-30$ & $<-160$ & $<-160$ & $<-160$ & $<-160$ & 40 & -140 & 70 \\
\hline 6 & $38-33.5-28.5$ & 2 & -65 & -51 & 36 & - & -35 & \\
\hline 7 & $37-35-28$ & 1 & -55 & -31 & 39 & 83 & -5 & \\
\hline 8 & $38-35-27$ & -15 & -34 & -7 & 17 & 113 & -5 & \\
\hline 9 & $37-36-27$ & 92 & 36 & 39 & 141 & 100 & 37 & \\
\hline 10 & $36-36-28$ & 40 & -1 & 27 & 54 & 67 & 35 & \\
\hline
\end{tabular}

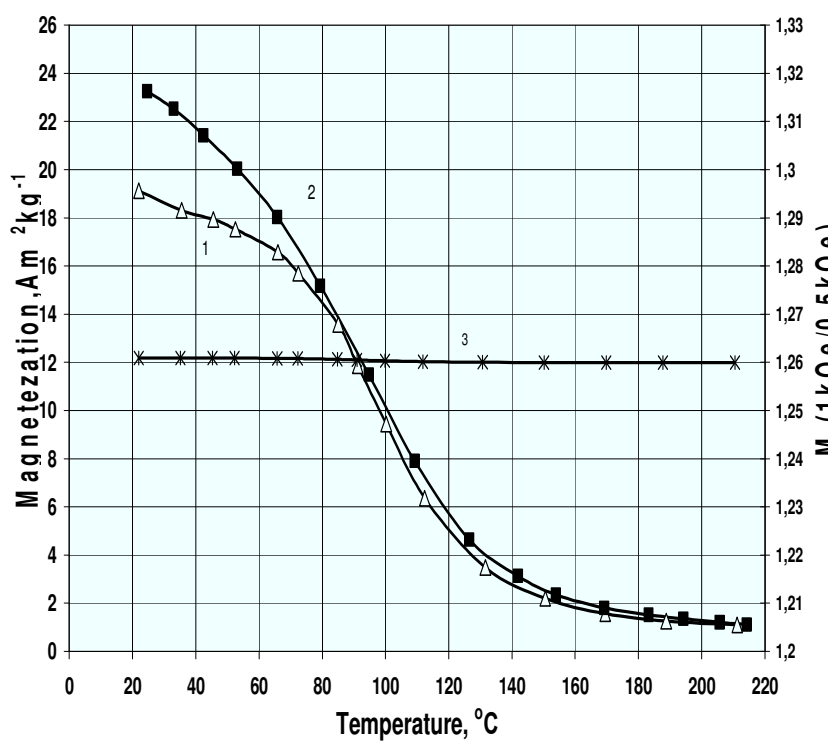

a

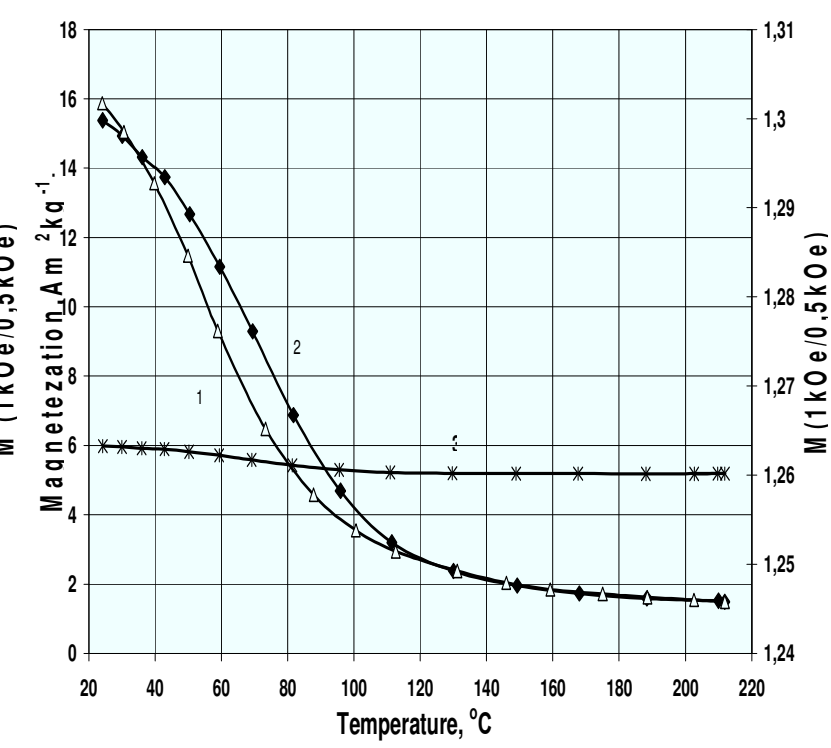

b

Fig. 4. Temperature dependence of the specific magnetization (M) of the $\mathrm{Co}_{38} \mathrm{Ni}_{34} \mathrm{Al}_{28}$ and $\mathrm{Co}_{36} \mathrm{Ni}_{36} \mathrm{Al}_{28} \mathrm{MC}$ alloys: 1 - heating in a field of $0,5 \mathrm{kOe} ; 2$ - cooling in a field of $0,5 \mathrm{kOe}$; 3 - the ratio of magnetizations in fields of $1 \mathrm{kOe} m$ and $0,5 \mathrm{kOe}$.

The presence of the classical SME shows up well qualitatively in strips of all the alloys, except the stable $\mathrm{Co}_{38} \mathrm{Ni}_{32} \mathrm{Al}_{30} \beta$-alloy, when they undergo bending deformation in liquid nitrogen. Thin strips, which are elastic in the austenitic $\beta$ state, become plastic in the martensitic $\mathrm{L} 1_{0}$ state upon cooling in liquid nitrogen, withstand bending through $180^{\circ}$ on a mandrel of diameter $1 \mathrm{~mm}$, and fully recover their rectilinear shape when heated to room temperature.

First encouraging results were obtained on a specially designed installation for measuring the elongation of strip samples in strong magnetic fields (Fig. 5). A weakly loaded ( $\sigma \approx 40 \mathrm{MPa}$ ) strip of the $\mathrm{Co}_{38} \mathrm{Ni}_{34} \mathrm{Al}_{28}$ alloy in the two-phase $\left(\beta+\mathrm{L}_{0}\right)$ state elongated approximately $0.01 \%$ (4 $\mu \mathrm{m})$ in a transverse magnetic field of $15 \mathrm{kOe}$. The melt-spun $\mathrm{Co}_{38} \mathrm{Ni}_{34} \mathrm{Al}_{28}$ alloy with the transformation temperatures $\mathrm{M}_{\mathrm{s}}=31^{\circ} \mathrm{C}, \mathrm{M}_{\mathrm{f}}=-34^{\circ} \mathrm{C}, \mathrm{A}_{\mathrm{s}}=-6^{\circ} \mathrm{C}, \mathrm{A}_{\mathrm{f}}=70^{\circ} \mathrm{C}$ and $\mathrm{T}_{\mathrm{c}}=98^{\circ} \mathrm{C}$ is a material possessing the magnetically controlled shape memory effect. 


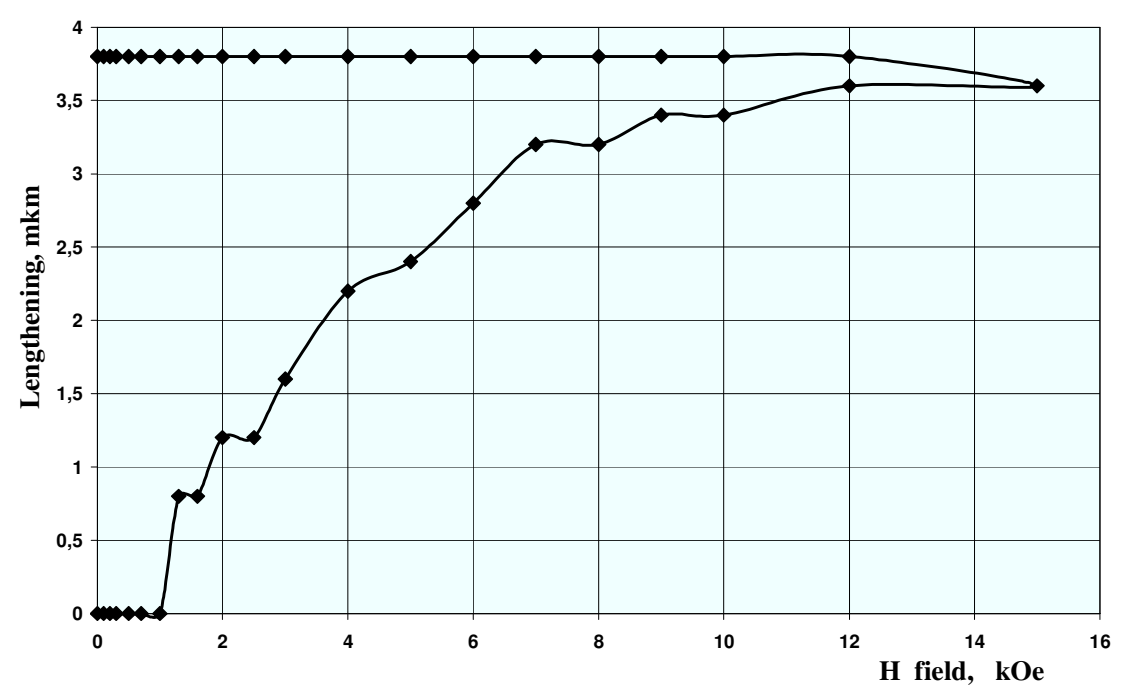

Fig. 5. Variation of the length of $\mathrm{MC}$ alloy $\mathrm{Co}_{38} \mathrm{Ni}_{34} \mathrm{Al}_{28}$ samples in a magnetic field (the magnetic field is perpendicular to the length of the sample and lies in its plane, measurements at $90^{\circ} \mathrm{C}$ ).

\section{Summary}

Refinement of grains to $1 \mu \mathrm{m}$ in ferromagnetic $\mathrm{Co}-\mathrm{Ni}-\mathrm{Al}$ alloys made by melt spinning decreases the martensite start temperature $\mathrm{M}_{\mathrm{s}}$ by $30-50^{\circ} \mathrm{C}$. Replacement of 1 at. $\%$ cobalt by nickel and 1 at. $\%$ aluminum by nickel makes the temperature interval of the $\mathrm{B} 2 \leftrightarrow \mathrm{L} 1_{0}$ martensite transformation $(30-60)^{\circ} \mathrm{C}$ and $(100-110)^{\circ} \mathrm{C}$ higher respectively. The melt-spun $\mathrm{Co}_{38} \mathrm{Ni}_{34} \mathrm{Al}_{28}$ alloy with the transformation temperatures $\mathrm{M}_{\mathrm{s}}=31^{\circ} \mathrm{C}, \mathrm{M}_{\mathrm{f}}=-34^{\circ} \mathrm{C}, \mathrm{A}_{\mathrm{s}}=-6^{\circ} \mathrm{C}, \mathrm{A}_{\mathrm{f}}=70^{\circ} \mathrm{C}$ and $\mathrm{T}_{\mathrm{c}}=98^{\circ} \mathrm{C}$ is a material possessing the magnetically controlled shape memory effect.

The authors wish to thank S.V. Kositsyn, A.I. Valiullin and N.V. Kataeva.

\section{References}

1. A.N. Vasiliev, V.D. Buchelnikov, T. Takagi, V.V. Khovailo, E.I. Estrin. Uspekhi Fiz. Nauk. Vol. 173 (2003) No. 6, p. 576.

2. V.A. Chernenko, E. Cesari, V.V. Kokorin, I.N. Scripta Metallurgica et Materialia. Vol. 33 (1995) No. 8, p.1239.

3. K. Oikawa, L. Wulff, T. Iijima, F. Gejima, T. Ohmori, A. Fujita, K. Fukamichi, R. Kainuma, K. Ishida. Applied Physics Letters. Vol.79 (2001) No. 20, p. 3290.

4. K. Oikawa, O.Takuya, G. Femihiko, O. Toshihiro, R. Kainuma, K. Ishida. Materials Trans. Vol. 42 (2001) No. 11, p. 2472.

5. Y. Murakami, D. Shindo, K. Oikawa, R. Kainuma, K. Ishida. Acta Materialia, Vol.50 (2002), p. 2173.

6. K. Oikawa, T. Omori, Y. Sutou, R. Kainuma, K. Ishida. J. Phys. IV France. Vol. 112 (2003), p. 1017.

7. S.V. Kositsyn, A.I. Valiullin, N.V. Kataeva, I.I. Kositsyna. The Physics of Metals and Metallography, Vol. 102 (2006) No. 6, p. 418.

8. X.J. Liu, K. Oikawa K, I. Ohnuma, R. Kainuma, K. Ishida. JOM. Vol. 55 (2003) No. 12, p. 53.

9. S.V. Kositsyn. Alloys and Coatings Based on Nickel Monoaluminide (Ekaterinburg, 2008).

10. S.V. Kositsyn, I.I. Kositsyna, A.I. Valiullin, N.V. Kataeva, V.A. Zavalishin. Perspektivnye materially. 3 (2005) p.56.

11. A.A. Arkhangelskaya, I.N. Bogachev, V.S. Litvinov, E.G. Pantsyreva. The Physics of Metals and Metallography, Vol. 34 (1972) No. 6, p. 541.

12. N.F. Kennon, D.P. Dunne, J.H. Zhu. Journal de physique IV. Vol. 5 (1995) p.1041. 